
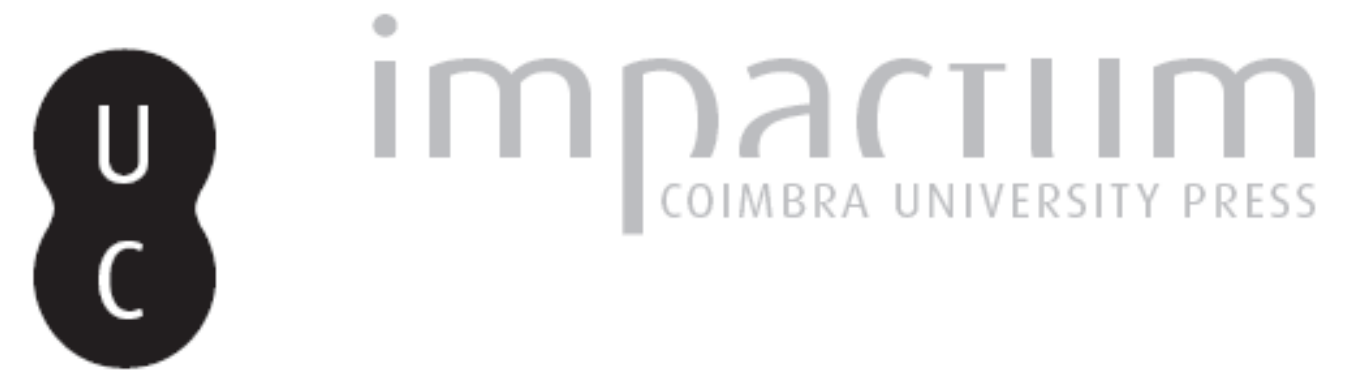

A difusão do conto português em Itália: o ano da graça de 2006

Autor(es): $\quad$ Simões, Manuel G.

Publicado por: Imprensa da Universidade de Coimbra

URL persistente: URI:http://hdl.handle.net/10316.2/42653

DOI: $\quad$ DOI:https://doi.org/10.14195/0870-8584_2_19

Accessed : $\quad$ 26-Apr-2023 14:50:01

A navegação consulta e descarregamento dos títulos inseridos nas Bibliotecas Digitais UC Digitalis, UC Pombalina e UC Impactum, pressupõem a aceitação plena e sem reservas dos Termos e Condições de Uso destas Bibliotecas Digitais, disponíveis em https://digitalis.uc.pt/pt-pt/termos.

Conforme exposto nos referidos Termos e Condições de Uso, o descarregamento de títulos de acesso restrito requer uma licença válida de autorização devendo o utilizador aceder ao(s) documento(s) a partir de um endereço de IP da instituição detentora da supramencionada licença.

Ao utilizador é apenas permitido o descarregamento para uso pessoal, pelo que o emprego do(s) título(s) descarregado(s) para outro fim, designadamente comercial, carece de autorização do respetivo autor ou editor da obra.

Na medida em que todas as obras da UC Digitalis se encontram protegidas pelo Código do Direito de Autor e Direitos Conexos e demais legislação aplicável, toda a cópia, parcial ou total, deste documento, nos casos em que é legalmente admitida, deverá conter ou fazer-se acompanhar por este aviso. 


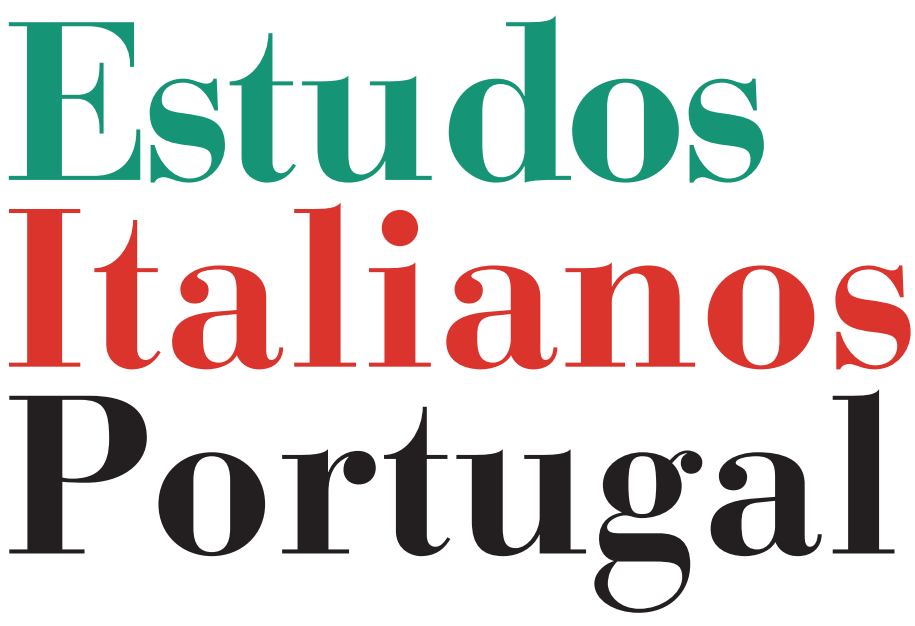

Instituto

Italiano

de Cultura

de Lisboa

Nova Série

$\mathbf{N}^{\mathbf{0}} 2$ 


\title{
A DIFUSÃO DO CONTO PORTUGUÊS EM ITÁLIA: O ANO DA GRAÇA DE 2006
}

\author{
Manuel G. Simões
}

No "Salão do Livro de Turim" de 2006, que decorreu de 4 a 8 de Maio, Portugal teve a honra de país convidado, razão por que o Instituto Português do Livro e das Bibliotecas (IPLB) e o Instituto Camões, em conjunto, conceberam um programa especial de apoio à tradução de autores portugueses por parte de editoras italianas. Se se considerar que se candidataram 20 editoras para um total de 30 obras a traduzir especificamente para serem apresentadas no "Salão", deve louvar-se o interesse e o empenho, em primeiro lugar de um número considerável de tradutores, quase todos docentes universitários de língua e literatura portuguesa, porque é deles que, de um modo geral, parte a iniciativa da tradução como pura e desinteressada operação cultural, visto que o seu trabalho não só não é, em geral, remunerado, como

* Manuel G. Simões é professor jubilado de literaturas portuguesa e brasileira da Universidade Ca' Foscari de Veneza. Poeta e ensaísta. Traduziu poemas de S. Quasimodo, E. Montale, Paolo Ruffilli, Franco Loi e Fabio Scotto; uma antologia de P. P. Pasolini e o livro de Tiziano Rossi, Gente di corsa (prémio "Poesia italiana contemporanea su internet", 2001). Traduziu para italiano o livro de poesia de Casimiro de Brito, Libro delle cadute. Pertence à redacção da revista Rassegna Iberistica (Veneza), de que foi um dos fundadores em 1978.

1 Paola D'Agostino, "Portugal em Turim”, in Estudos Italianos em Portugal, nova série, $n^{\circ} 1,2006$,pp. 423-426. 
ainda fica dependente de encontrar os "favores" de um editor disponível; e, em segundo lugar, das instituições portuguesas, prontas a apoiar, num espaço de tempo limitado, a divulgação, no estrangeiro, de autores portugueses que, por uma razão ou por outra, mereceram a atenção dos editores (ou dos tradutores) italianos.

A este respeito convém dizer que o Instituto Camões e o IPLB deveriam talvez estabelecer um critério mais rigoroso na atribuição de subsídios como apoio à tradução (na prática, como se disse, trata-se de apoio à edição), dado que a maior parte das editoras tem uma actuação regional - a geografia italiana é bem diferente da portuguesa -, não entram na rede de distribuição nacional e, como tal, as obras não chegam a ter grande visibilidade, e o impacto é, como se compreende, limitadíssimo. No caso específico, isto é, considerando as editoras italianas que publicaram as obras apresentadas em Turim, são relativamente conhecidas a "Donzelli", a "Cavallo di Ferro" ou "La Nuova Frontiera", de Roma; a "Diabasis", de Reggio Emilia ou a "Besa", de Nardò (Lecce); e sem dúvida a "Guanda", de Parma. A título de exemplo, quem escreve estas linhas fez uma experiência em Outubro de 2006 nas livrarias mais importantes de Pádua e Veneza, e não encontrou um só título de autor português dos trinta que tinham sido lançados no "Salão". É caso para repensar, quanto a mim, a questão do apoio à edição, equacionando o esforço financeiro e a contrapartida oferecida pelos editores candidatos ao subsídio: o grau de divulgação, os circuitos de distribuição, a eventual garantia de visibilidade proporcionada ao leitor italiano e o possível interesse que as obras possam despertar na imprensa cultural do país: em Itália traduzem-se inúmeras obras mas, como se compreende, só um pequeno grupo é mencionado pelos jornais e revistas, com um critério de selecção semelhante ao que vigora entre nós. Apesar destas limitações, é de salientar a tradução de um número considerável de títulos. E como os tradutores são 
sempre lusitanistas que trabalham em várias universidades italianas, os livros serão, pelo menos, lidos pelos alunos de cada responsável pela edição, o que os subtrai ao grau zero de divulgação.

De entre os muitos títulos, saliente-se a coincidência de várias antologias do conto português - rivalizando, desta vez, com o interesse quase predominante pela poesia -, e retomando as iniciativas, já longínquas, de, por exemplo, Le più belle novelle dell'Ottocento, com prefácio de Mario Bonfantini (Roma, Casini Ed., 1951); Pagine della letteratura portoghese, org. de P.A. Jannini (Milano, Nuova Accademia, 1955), que reúne poesia da Idade Média até Florbela Espanca e que inclui alguns prosadores contemporâneos; e Carosello di narratori portoghesi, org. de Enrico Cicogna (Milano, Aldo Martello Ed., 1963). E como as antologias agora propostas não se sobrepõem - para além da repetição inevitável de um ou outro autor e de um ou outro conto -, seguem critérios e perspectivas diversificados, serão também aqui analisadas separadamente, de modo a evidenciar os traços distintivos de cada uma.

\section{QuANDo IL DiAVOLO CI METTE LA CODA ${ }^{2}$}

É uma antologia relativamente breve, composta apenas de sete contos, revisitando outros tantos autores: Alexandre Herculano ("A Dama Pé-de-cabra”), com tradução de Rosaria de Marco; Júlio César Machado ("Uma récita do Roberto do diabo"), na versão de Alessandra d'Aragona; Júlio Dinis ("O Canto da Sereia"), trad. de Virginia Zehender; Fialho de Almeida ("Conto do almocreve e do diabo"), trad. de Maria Luisa Cusati; Raul Brandão ("O Mistério da Árvore”),

2 Quando il diavolo ci mette la coda. Racconti fantastici portoghesi a cura di Maria Luisa Cusati, Napoli, L’Ancora del Mediterraneo, 2006, pp. 191. 
ainda com trad. de Alessandra d'Aragona; António Patrício ("Diálogo com uma águia”), versão de Maria da Graça Gomes de Pina; e Mário de Sá-Carneiro ("A estranha morte do professor Antena"), de novo com tradução de Rosaria de Marco. Cada conto é precedido por uma nota bio-bibliográfica do autor, em geral exauriente, pelo título original do conto e, aspecto importante, pela edição que serviu de base para a tradução. Os contos aqui apresentados tiveram, como vimos, diversas tradutoras. Mas tal como diz Maria Luisa Cusati na sua "premessa"

"la traduzione a carico di varie persone non è però segno di lavori autonomi e distaccati. Si è trattato di un lavoro di gruppo in cui ciascuno ha sottoposto agli altri i problemi, i dubbi, le difficoltà di comprensione di elementi culturali

lontani nel tempo che di mano in mano incontrava, ricorrendo se necessario anche a consulenze esterne" (p. 14).

Na selecção dos contos, foram privilegiados os que apresentam "contorni nebulosi e intriganti considerati tipici del fantastico" (p.10) de que é paradigmático o famoso conto de magia demoníaca que tem como título "A Dama Pé-de-cabra", de inspiração medieval (Nobiliários) e por isso com uma escritura mais árdua de traduzir. Diga-se, desde já, que Rosaria de Marco conseguiu dar-nos em italiano um texto fluente, com alguns problemas sobretudo em relação a termos arcaicos mas que não inquinam a atmosfera textual do conto de A. Herculano. Não concordo, todavia, com a versão do título ("Madonna pièdicapra"), talvez na tentativa de recuperar o uso do antigo apelativo de reverência relativamente à mulher, quando conviria o simples decalque ("dama"), de resto utilizado 
algumas vezes no corpo do texto. Notam-se, ainda, algumas incertezas na interpretação do termo medieval "rico-homem" (elemento da nobreza); e a forma "Sant'Iago" (p. 19) correspondente ao português "Santiago" é seguramente incorrecta.

Quanto aos outros contos, apenas breves observações em matéria de tradução. Assim, em "O Mistério da Árvore", de Raul Brandão, belíssimo texto mas de algum modo estranho ao cânone do fantástico seguido pela antologia, a palavra "espanto" não corresponde, no contexto, ao italiano "spavento" (p. 140); e no conto de António Patrício, à palavra "corso", a que se refere o texto e a nota ("corso di uno zoo"), creio que seria preferível a forma "viale" (p. 145). No seu conjunto, porém, a antologia revela uma atenção apreciável à tradução, fazendo respirar os textos de partida mas sem transcurar a especificidade linguístico-literária de narrativas susceptíveis de interessar, pelo seu grau de sugestão, o leitor italiano.

\section{Antologia Del RACCONTO PORTOGHESE ${ }^{3}$}

Diferente, como metodologia e como abordagem à narrativa breve que se produz em Portugal, é esta antologia que reproduz, quase integralmente, a antologia organizada por João de $\mathrm{Melo}^{4}$, com a inclusão agora de um conto do próprio João de Melo ("Oro in pianto"), que não figurava na edição portuguesa, e a exclusão de Jacinto Lucas Pires, sem que, porém, se explique a razão das duas alterações.

3 Antologia del racconto portoghese, a cura di João de Melo, traduzione e cura italiana di Vincenzo Barca, collaborazione di Renata Belardinelli, Roma, Cavallo di Ferro, 2006, pp. 575 [introduzione di V. Barca, postfazione di João de Melo].

4 Antologia do Conto Português, organização, prefácio e notas de João de Melo, Lisboa, Pub. Dom Quixote, 2002 (3 ed., 2005), pp. 523. 
Como se diz no prefácio de Vincenzo Barca, a antologia

"si apre con alcuni dei racconti più "classici" dell'Ottocento portoghese $(\mathrm{La}$

Dama Piè-di-capra di Alexandre Herculano, Come lo amava! di

Camilo

Castelo Branco e Singolarità di una ragazza bionda di Eça de Queirós) per proseguire con i nomi più significativi dell'universo letterario portoghese del Novecento" (p. 5).

$\mathrm{Na}$ verdade, se já a edição portuguesa produz uma escolha demasiado alargada porque se estende a autores quanto a mim não muito significativos ou não reconhecidos entre o grupo dos grandes contistas da literatura portuguesa (mas onde se verifica a lacuna imperdoável de Fernando Namora e dos belíssimos contos de Retalhos da Vida de um Médico, por exemplo); e se o responsável pela edição italiana (João de Melo ou Vincenzo Barca?) eliminou pelo menos um autor, creio que tal edição poderia ter "mondado" uns tantos autores por duas ordens de razões: ou porque já significam um "excesso" em terra própria; ou porque foram incluídos por se tratar de grandes romancistas ou poetas, embora a sua projecção como contistas não seja reconhecida.

Seguindo a edição portuguesa, também a Antologia del racconto portoghese faz preceder cada conto duma ficha bio-bibliográfica do Autor, acrescentando agora uma lista das traduções italianas do mesmo, com a finalidade de fornecer ao leitor um suplemento de informação quanto a outras obras traduzidas e quanto à "diffusione della produzione letteraria portoghese in Italia" (nota de p. 6). Deve dizer-se, a este respeito, que a indicação das traduções padece de muitas lacunas, como no caso de Eça de Queiroz, de quem se diz que os seus "romanzi però sono ormai introvabili e 
comunque affidati a traduzioni datatissime" (p. 5). E se é verdade, como afirmou Antonio Tabucchi, que o Autor ainda não teve em Itália o reconhecimento editorial adequado à sua grandeza e que consistiria na publicação da obra completa, traduzida, estudada e anotada com competência ${ }^{5}$, também não se pode dizer que Eça não tenha sido traduzido ao longo dos séculos XX e XXI e várias vezes reproposto 6 . Vincenzo Barca, porém, só menciona as traduções publicadas a partir de 1989; e se não se justificava o elenco de todas as traduções, até por motivos de espaço, podia ao menos ter informado o leitor que Eça começou a ser traduzido para italiano em 1913 (A Relíquia) e que o conto inserido na antologia já tinha conhecido outras versões. Com efeito, "Singolarità di una ragazza bionda" (pp. 39-66) foi proposto com os títulos "Una strana ragazza bionda" (trad. de Mario Puccini, Milano, UE, 1953), "Stranezze di una ragazza bionda" (trad. de Camillo Berra, Torino, UTET, 1953) e "Singolarità di una ragazza bionda" (Racconti, int., trad. e note di Davide Conrieri e Maria Abreu Pinto, Milano, Rizzoli, 2000, pp. 67-97).

Mas outros autores há dos quais não resulta terem sido objecto de tradução italiana, como Aquilino Ribeiro, José Rodrigues Miguéis, Vitorino Nemésio, Domingos Monteiro, Soeiro Pereira Gomes, Manuel da Fonseca, por exemplo, e que, pelo contrário, foram a seu tempo divulgados em Itália. De José Cardoso Pires, de quem se afirma ser "autore 'impegnato', arrivatoci subito dopo la Rivoluzione del '74" ("Introduzione”, p. 6), não se refere a publicação de L'ospite di Giobbe (trad. de Arrigo Peppeto, Milano, Lerici,

${ }^{5}$ Cfr. Antonio Tabucchi, "Splendori e miserie di Eça de Queirós", in Indice, $\mathrm{n}^{\circ} 3,2000$, p. 12.

${ }^{6}$ Veja-se Manuel G. Simões, “A recepção literária de Eça de Queiroz em Itália”, in Eça, Antero e a Geração de 70. Actas do colóquio (8, 9 e 10 de Novº. de 2000) de Vila do Conde, Estudos Anterianos, n ${ }^{\circ}$ 9-10, Abril-Nov ${ }^{\circ}$ de 2002, pp. 55-62. 
1963); a primeira edição de Il delfino (Roma, Ed. Riuniti, 1979); ou Ballata della spiaggia dei cani (trad. de Rita Desti, Milano, Feltrinelli, 1985).E de Mário Cláudio não se menciona La tela del sogno (racconti, Roma-L'Aquila, Japadre, 1993). Algumas destas edições já não se encontram no mercado, é certo, mas, neste contexto, teria sido útil a sua menção como indicação bibliográfica, tanto mais que, como se disse, a função do elenco dos títulos traduzidos era a de avaliar a difusão, em Itália, da produção literária portuguesa.

Sobre a tradução, na impossibilidade de produzir aqui uma análise sistemática da metodologia seguida, limito-me a apontar, entre os muitos casos de incompreensão do texto de partida, alguns exemplos em que, no plano do conteúdo, se efectuou um desvio acentuado e inexplicável, de modo que o produto da mediação não "diz quase a mesma coisa", para aplicar aqui o título de um famoso ensaio de Umberto Eco sobre experiências de tradução. Vejamos o conto "La dama piè-di-capra" de A. Herculano, de que se traduz apenas um pequeno fragmento, seguindo a antologia portuguesa, mas sem disso informar o leitor. Vincenzo Barca não segue um critério uniforme, visto que para a expressão "almas penadas" escolhe umas vezes "anime in pena" (p. 13) e outras "anime dannate" (p. 19), escolha esta talvez mais de acordo com a situação contextual; e o mesmo acontece com o português arcaico "a la fé", vertendo-o quer em "sulla mia fé" (p. 14), seguindo um registo antigo, quer como "in fede" (p. 17).

Mas onde a deturpação atinge um grau mais elevado é porventura em "L'immagine della Madonna", de Aquilino Ribeiro, um autor dificil, sem dúvida, mas por isso mesmo a exigir uma leitura mais atenta. Para além de algumas omissões textuais, não despiciendas, eis alguns casos de evidente falta de ponderação: assim a "dando-lhe a salvação" não pode corresponder "dandogli l'assoluzione" (p.140), porque 'salvar' é aqui usado no sentido de 'saudar'; "cortado a direito" 
não é propriamente "infilato a destra" (p. 142), visto que a tradução correcta deveria ser "tirar dritto"; o sintagma "Ficava a sua casinha [...] mesmo à saída de portas" não pode ser traduzido por "Eccola la sua casetta [...] inclusi gli usci delle porte" (p. 143), não tendo o tradutor entendido que se tratava da localização da casa; e, já agora, seria de manter a bela imagem das "taroquinhas palreiras das cachopas" do texto original, sem a banalizar, e até anular, com a versão "ciarle pettegole delle ragazze" (p. 141).

Sem querer aprofundar os problemas da tradução, dadas até as dimensões da antologia, relevem-se, porém, algumas soluções discutíveis exibidas pelo conto "Omero", de Sophia de Mello Breyner Andresen - mais cuidada e rigorosa é a tradução de Ambrogio Raso inserida em Racconti esemplari (Bari, Adriatica, 1993) - com segmentos textuais que chegam a ser paráfrase do texto de Sophia: veja-se "um monumento manuelino" que se transforma em "uno di quei monumenti dell'epoca del re Dom Manuel I" (p. 299); a não atenção aos "falsos amigos" no conto "Il racconto dei cinesi", de José Cardoso Pires, onde o lexema 'testa' não tem em conta o significado diverso nas duas línguas (p. 374), ou a expressão "riram ambas da partida" ("entrambe risero della partenza", p. 381), sem considerar o valor contextual que teria levado Renata Belardinelli ao verdadeiro correspondente e que seria, neste caso, "scherzo"("battuta", etc.). A mesma tradutora, entre outras desatenções ao longo do conto "Erika e l'alba", de David Mourão-Ferreira, traduz a expressão "muito boa menina" por "buonissima bambina" (p. 392), numa contradição e ambiguidade latentes até porque, imediatamente a seguir, a "menina" está ligada a um "sontuoso vestito da sposa"; e no conto "Di Barnabé capo cuoco della nave capitana nel primo viaggio sulla via delle Indie", de Mário Cláudio, R. Belardinelli volta a subverter o texto original, traduzindo "e de coisas de botica" por "altri viveri" (p. 472), "certa banqueta" por "certo banchetto", sem 
ter presente a transferência de significado, e ainda "de volta do meu lume" por "di ritorno dai miei fornelli" (p. 474), quando a situação contextual a deveria conduzir à expressão "intorno a".

\section{LUSITANIA EXPRESS}

Com diversa perspectiva é a antologia organizada por António Fournier, cujo ponto de partida lhe confere uma certa originalidade se considerarmos o subtítulo " 20 storie per un film portoghese"7, a transformação dos vinte autores em "attori protagonisti di questo film" e dos vinte tradutores em "doppiatori che ho avuto modo di coordinare durante i vari laboratori di traduzione letteraria nelle Università di Torino, Milano e soprattutto Pisa, da dove proviene la maggior parte di loro" (p. 201). São, pois, vinte os autores seleccionados entre os novíssimos criadores literários portugueses, com a particularidade de terem publicado as primeiras obras entre 1986 (Miguel Esteves Cardoso) e 2005 (Jorge Reis-Sá). O número 20 não pretende ser arbitrário e nem sequer a data de 1986, visto que são vinte os "anos europeus" de Portugal, considerando A. Fournier que 1986 é a "data simbolica dell'ingresso del Portogallo in Europa" (p. 201).

Como já se sabe, cada antologia é irrepetível e irrecusável, uma vez estabelecidos e declarados os critérios do responsável pela selecção. Mas se aceitamos como válida a afirmação de que a vitalidade do conto é "uno degli aspetti più interessanti che contraddistinguono gli anni più recenti" (p. 204), já não se percebe a escolha do texto de Rui Miguel

7 Lusitania Express. 20 storie per un film portoghese. Traduzione a cura di António José Gomes Fournier, Villa San Secondo (Asti), Scritturapura Editore, 2006, pp. $198+21$. 
Saramago, dado que se trata do primeiro capítulo do seu romance $A$ Hora das Neblinas e, como tal, descontextualizado; e a "apressada" inclusão do conto inédito "Acqua", de Jorge Reis-Sá, ou de "Istanbul senza metafisica", de Paulo José Miranda, publicado na revista Tabacaria, por se tratar de autores que até hoje não publicaram qualquer livro de contos, sendo o primeiro mais conhecido como editor e como organizador de antologias de poesia contemporânea.

No posfácio que António José Gomes Fournier dedica ao volume, intitulado "Made in Portugal", afirma-se que

"questa è una generazione alle prese com la perdita della memoria, con una frattura nell'immaginario, che non vuole più spiegare il passato, fare una

rivisitazione storica del Portogallo [...], delle conseguenze dell'arrivo del 25

aprile sulla famiglia tradizionale portoghese" (p. 208),

como acontecia com a geração precedente. Para além de não ser nunca nítida e brusca a passagem geracional e de ser prematura a periodização estabelecida, saliente-se que o próprio corpo textual em análise não permite uma generalização tão peremptória: basta pensar, por exemplo, no belíssimo conto de Frederico Lourenço ("Il giovane indù"), onde o núcleo da fabula reconstrói o passado adolescencial do protagonista, com os acontecimentos de 1974 a marcarem a função dos actantes. E, já agora, seja-me permitido discordar da opinião de A. Fournier quando afirma que autores como Vergílio Ferreira, Miguel Torga ou David Mourão-Ferreira já não são actualmente lidos e que Um Amor Feliz (1986; $15^{a}$ edição, 2002)) é hoje "semplicemente illeggibile, corroso dall'usura del tempo" (p. 206).

Voltando à antologia, convém dizer que as "20 storie per un film portoghese" seriam, quanto muito, aceitando a boutade 
cinematográfica, vinte episódios sem um fio condutor, o que contraria a opinião de A. Fournier, visto que, segundo ele, evidenciam "un labile confine, una soglia invisibile" (p. 207); e ainda que o trabalho de dobragem, como aqui explicitamente se inscreve na "ficha técnica" do filme, tem regras e metodologias que não são as da tradução literária. Daí as muitas desatenções dos "doppiatori” e que escaparam ao coordenador, as mais evidentes das quais são talvez as que se verificam no texto de Rui Miguel Saramago. Aqui, além de escolhas inaceitáveis ("criptográficas" resulta em italiano "incomprensibili", p. 119; "inédito" é traduzido por "insolito" e "requintadas" por "nascoste", p. 121, por exemplo) há casos de desvio de sentido por interpretação errada ou por não individuação da polissemia da palavra: "mas de manhã não desapareceu [a névoa], e por isso anda agora tudo numa aflição", de que resulta, por incompreensão da segunda parte, "ma al mattino non era sparita e adesso avanza ancora compatta in un'angoscia" (p. 119); "muitos se viciam" traduzido por"sono tutti corrotti" (p. 120); ou "o metereologista observa o longo passeio que acompanha o rio",com a absurda solução "il meteorologo osserva la lunga passeggiata che accompagna il fiume" (p. 122).

\section{L'ANIMA NAVIGANTE}

Por mera coincidência, esta outra antologia de contos portugueses, primeiro inserida na revista Crocevia e depois em volume 8 , também apresentada no "Salone del Libro di

8 L'anima navigante. Racconti dal Portogallo, a cura di Gianluca Miraglia e Marcello Sacco, Nardò (Lecce), BESA Editrice, 2006, pp.172. Saliente-se a importância concedida por esta editora a autores portugueses ou de língua portuguesa, tendo publicado obras de Vergílio Ferreira (Addio e altri racconti e Apparizione), Almeida Faria (Le passeggiate del sognatore solitario e Il Conquistatore), Agustina Bessa-Luís (Fanny Owen), José Gil (Mostri), Pepetela (Parabola della vecchia tartaruga), Moisés Espírito Santo (Fatima magica). 
Torino", selecciona igualmente vinte autores que, segundo os organizadores, "testimoniano la vitalità della narrativa breve in Portogallo nel periodo fra il 1990 e il 2005" (p. 7), o que corresponde praticamente ao mesmo espaço de tempo considerado pelo volume de A. Fournier. E, todavia, dos vinte autores, apenas cinco aparecem nas duas antologias (Miguel Miranda, Pedro Paixão, José Riço Direitinho, Manuel Jorge Marmelo e Jacinto Lucas Pires), embora com textos diferentes. Quer dizer, G. Miraglia e M. Sacco partiram de critérios que, do ponto de vista crítico, me parecem mais "científicos" e que expõem com tansparência:

"sono stati di grande utilità i premi attribuiti da giurie di rico nosciuta autorevolezza [...], le segnalazioni della critica in libri e riviste, e naturalmente una pratica di lettura continuata che da vari anni cerca di seguire la narrativa portoghese contemporanea" (pp. 11-12).

Deste modo, a escolha contemplou sobretudo autores de segura e confirmada afirmação na história das ideias literárias em Portugal, independentemente da idade cronológica, mas cuja escrita oferece uma visão válida da actividade literária actual, propondo situações e personagens de alguma maneira distintivas da realidade portuguesa das duas últimas décadas. Creio que são consensuais os nomes de Maria Judite de Carvalho, Urbano Tavares Rodrigues, José Cardoso Pires, Fernanda Botelho, Maria Velho da Costa, Armando da Silva Carvalho, Teolinda Gersão, António Lobo Antunes, Mário de Carvalho, José Viale Moutinho, Lídia Jorge, António Mega Ferreira, Luísa Costa Gomes e Nuno Júdice, dos quais somente o último é sobretudo identificado como poeta. Os organizadores têm, contudo, plena consciência dos limites e da responsabilidade de juízo crítico quando se 
organiza uma antologia e, acima de tudo, como no caso específico, quando

"si opera a caldo, a ridosso della scrittura e della pubblicazione,

quando

lo sguardo critico non può godere della distanza che permette una maggior

serenità e sicurezza nella valutazione dei valori e nella definizione di un

canone in grado di sfidare il tempo" (p. 12).

Apesar de terem que considerar um cânone flutuante - o qual, porém, encontra um grau estabilizador na confluência de modos como se observa a sociedade contemporânea, e não apenas portuguesa -. G. Miraglia e M. Sacco assumem e explicitam os critérios de maneira exemplar:

“offrire al lettore italiano un'immagine coerente della narrativa

breve portoghese degli ultimi quindici anni, proponendogli

autori più significativi e i loro racconti migliori. Il criterio estetico, pur se naturalmente discutibile, gioca insomma un ruolo fondamentale e si sovrappone a quello della semplice rappresentatività" (p. 12).

A tradução, a cargo de Gianluca Miraglia, Marcello Sacco, Paola D'Agostino e Cristiana Bambini, é em geral cuidada; procura observar as equivalências relativamente ao texto de partida sem que isso determine a perda de intensidade da expressão linguístico-literária. Para se avaliar da meticulosidade e competência postas no acto de traduzir, podem confrontar-se os contos de José Viale Moutinho ("I trabocchetti del sole") e de Lídia Jorge ("Marito"), traduzidos aqui por Marcello Sacco e inseridos igualmente na antologia de João 
de Melo9. Quanto ao primeiro conto, e ao contrário de MS, aquela antologia eliminou a epígrafe do Autor, contudo presente na edição portuguesa, e que tinha como função a criação do contexto; a expressão "mas cachorros da PVDE, os pevides, as sementes da tortura" foi resolvida por RB como "ma i cani del PVDE, i "pevides", le sementi della tortura" (p.510), decerto incompreensível para o leitor italiano, enquando MS, mais atento, não só mantém o género feminino ("della PVDE") como explica, em nota, que pevides eram "gli agenti della polizia politica salazarista che, all'epoca dei fatti narrati, si chiamava PVDE - Polícia de Vigilância e Defesa do Estado" (nota de p. 73). E quando ao segundo, isto é, o conto de Lídia Jorge, as divergências, para além de substanciais, de resto já verificáveis no primeiro caso (veja-se a expressão "com o balde entre portas", por exemplo, que RB traduz de modo absurdo por "com quella doccia fredda sulla soglia della porta", p. 521, e MS justamente por "Con il secchio sul pianerottolo", p. 83), são também de ordem formal, mostrando-se RB hesitante quanto às expressões latinas da oração pronunciada, ao longo do texto, pela voz narrante, ora traduzindo-as ora não, o que contrasta com a metodologia de MS, que as manteve sempre.

L'anima navigante é uma proposta aberta e validíssima no sentido que parte de uma escolha equilibrada entre o que se produziu, nos últimos quinze anos, no âmbito da narrativa breve portuguesa. E com a intenção de "explicar" o contexto sócio-cultural em que esta literatura se produziu, os antologiadores publicam, como "apêndice", dois textos de grande interesse e que marcaram o pensamento português naquele espaço de tempo: um fragmento datado de 20/12/1994 e extraído de Cadernos de Lanzarote. Diário II,

9 Cfr. Antologia del racconto portoghese, ed. cit., pp. 509-514 e 517-526, respectivamente. A tradução é de Renata Belardinelli, aqui designada por RB; a sigla MS designa evidentemente Marcello Sacco. 
de José Saramago, e que G. Miraglia e M. Sacco intitularam "Quando si chiede a un portoghese una definizione del suo Paese" (pp.147-152); e um capítulo de Portugal Hoje, O Medo de Existir (2004), do filósofo José Gil (pp.153-163) sobre a mentalidade portuguesa, as transformações sociais depois do salazarismo e as relações entre literatura e "espaço público".

\section{LUSOFÔNICA $^{10}$}

Alargando deliberadamente o âmbito espacial ao mundo da chamada Lusofonia, esta antologia de narrativas breves contempla as literaturas portuguesa (8 autores), angolana (1), moçambicana (3) e brasileira (7), sendo a secção portuguesa introduzida por um texto de Lídia Jorge ("Gli anni del garofano"), memória paradigmática do ano que a grande escritora recorda como "l'inizio tardivo dell'epoca postcoloniale pronunciata in lingua portoghese" (p.20); a africana precedida por um breve mas lucidíssimo discurso de Pepetela ("Gli anni Settanta"), o qual acentua o fim da secular teoria imperialista de um país pluricontinental, multirracial e multi-étnico (p. 77) mas também a ingerência das grandes potências mundiais (p. 78); e a brasileira, contextualizada por uma introdução de Moacyr Scliar ("Memorie della repressione"), que, de forma sucinta e clara reconstrói a evolução histórico-política de toda a América Latina nos anos 60 e 70, em particular a que se viveu no Brasil da ditadura militar e seus reflexos na literatura. São três testemunhos destinados a determinar um contexto e, como tal, funcionam como indicadores perlocutórios a cada uma das secções.

São explícitos os critérios que orientaram Giorgio de Marchis na preparação de uma antologia cujo produto representa,

${ }^{10}$ Lusofônica. La nuova narrativa in lingua portoghese, a cura di Giorgio de Marchis, Roma, La Nuova Frontiera, 2006, pp. 166. 
como se viu, uma escolha (entre outras possíveis) da área da Lusofonia, o que significa que todos os contos, ainda que de autores provenientes de três continentes e de quatro nações (Portugal, Angola, Moçambique e Brasil), foram escritos em língua portuguesa. Para além desta premissa de carácter geral, o critério mais distintivo diz respeito ao factor geracional: "i diciannove scrittori selezionati sono, infatti, nati tutti negli anni Settanta e hanno pubblicato la loro prima opera dopo il 1995" (p.10), o que determina uma antologia de autores da chamada "geração de 90", seguindo uma terminologia já consolidada em Portugal, por exemplo, pelo excelente ensaio de Miguel Real (Geração de 90. Romance e Sociedade no Portugal Contemporâneo, Porto, 2001) e igualmente no Brasil através dos estudos de Nelson de Oliveira: Geração 90: Manuscritos de computador, São Paulo, 2001; e Geração 90: os transgressores, São Paulo, 2003. Isto quer dizer que o período contemplado coincide, em larga medida, com o das antologias de António Fournier e de Gianluca Miraglia/Marcello Sacco, pelo que não surpreende, relativamente ao sector português, a sobreposição de autores, embora com textos diversos, sobretudo entre Lusofónica e Lusitania Express (Jacinto Lucas Pires, Manuel Jorge Marmelo, José Luís Peixoto, Gonçalo M. Tavares e Jorge Reis-Sá), já que L'anima navigante, mais atenta à estética da narrativa breve portuguesa, apenas regista dois destes nomes: Manuel Jorge Marmelo e Jacinto Lucas Pires. De facto, como já se disse em relação ao critério de A. Fournier, também Giorgio de Marchis não pretendeu estabelecer un cânone antológico, visto que, com muita frequência, inseriu materiais inéditos, como no caso dos portugueses António Gregório e Gonçalo M. Tavares; dos moçambicanos Rogério Manjate e Pedro Muiambo; ou dos brasileiros Ferrez e Santiago Nazarian, para não falar de Filipa Melo e Jorge Reis-Sá, cujos contos foram extraídos de revistas. 
A tradução, de Francesca Di Giuseppe, que se ocupou dos autores portugueses, de Matilde Genovese dos africanos, e de Patrizia di Malta dos brasileiros, é em geral fluente, deixando perceber as virtualidades do texto de partida. É verdade que, na transposição textual, há sempre qualquer coisa que se perde (cito, ao acaso, a esplêndida imagem da "alforreca" do conto de Ondjaki, que se dilui banalmente em "sorgente") mas o resultado global é francamente positivo. No texto do brasileiro Ronaldo Bressane pode concordar-se que P. di Malta tenha deixado em português os segmentos textuais da famosíssima bossa nova "eu sei que eu vou te amar" (p. 139), por ser muito conhecida mesmo a nível internacional, mas o mesmo não acontece com a canção "voltei, recife, foi a saudade que me trouxe pelo braço" (p. 140), menos divulgada e até linguisticamente mais distante do falante italiano; em qualquer dos casos, quanto a mim, teria sido útil oferecer a tradução em nota, acrescentando algumas notícias sobre as canções, os autores e, eventualmente, os seus intérpretes.

Com menor ou maior circulação, com um grau de visibilidade que pode não atingir a difusão que se desejaria, as cinco antologias marcaram, a diversos níveis, um ano excepcional relativamente à recepção literária do conto português em Itália. É claro que é justo evidenciar as que partiram de uma investigação e selecção pessoais, operação que pressupõe uma leitura crítica de um corpus textual imenso até chegar ao produto final e à tentativa de fixar um cânone. Este último aspecto só terá sido conseguido pela antologia de Maria Luisa Cusati, dado que a sua atenção incidiu sobre o conto fantástico, enquanto as outras quatro se confrontaram com problemas que tornavam dificil essa fixação: ou pela proximidade de publicação, sem o necessário distanciamento (nos casos de A. Fournier, de G. Miraglia/M. Sacco e de G. de Marchis) ou pela dimensão, talvez excessiva, da 
antologia de João de Melo/V. Barca, reunindo cinquenta autores que vão desde o nascimento, no século XIX, da narrativa breve (Alexandre Herculano) até ao dealbar do séculoXXI (José Luís Peixoto).

Seja como for, as cinco antologias assinalam, na literatura portuguesa, o florescimento de um género que se espera possa ser fruído pelo leitor italiano, se a sua circulação o puder estimular e conduzir ao prazer da leitura. 